\title{
PCV2 replication promoted by oxidative stress is dependent on the regulation of autophagy on apoptosis
}

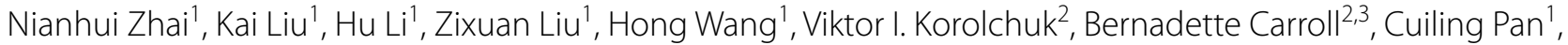 \\ Fang Gan ${ }^{1}$, Kehe Huang ${ }^{1}$ and Xingxiang Chen ${ }^{1 *}$ (D)
}

\begin{abstract}
Porcine circovirus type 2 (PCV2) is an economically important swine pathogen but some extra trigger factors are required for the development of PCV2-associated diseases. By evaluating cap protein expression, viral DNA copies and the number of infected cells, the present study further confirmed that oxidative stress can promote PCV2 replication. The results showed that oxidative stress induced autophagy in PCV2-infected PK15 cells. Blocking autophagy with inhibitor 3-methyladenine or ATG5-specific siRNA significantly inhibited oxidative stress-promoted PCV2 replication. Importantly, autophagy inhibition significantly increased apoptosis in oxidative stress-treated PK15 cells. Suppression of apoptosis by benzyloxycarbonyl-Val-Ala-Asp fluoromethylketone in conditions of autophagy inhibition restored PCV2 replication. Taken together, autophagy protected host cells against potential apoptosis and then contributed to PCV2 replication promotion caused by oxidative stress. Our findings can partly explain the pathogenic mechanism of PCV2 related to the oxidative stress-induced autophagy.
\end{abstract}

\section{Introduction}

Porcine circovirus type 2 (PCV2), the smallest autonomously replicating animal virus, belongs to genus Circovirus of the Circoviridae family, and this virus is icosahedral, non-enveloped, with a covalently closed circular single-stranded DNA [1]. PCV2 is the primary causative agent of several syndromes known as PCV2associated diseases [2], which has caused considerable economic loss in the swine industry [3]. However, not all pigs infected with PCV2 will develop PCV2-associated diseases. Actually, PCV2 alone rarely causes disease [4]. Several studies have reported that other trigger factors such as oxidative stress [5, 6], immune stimulation [7], presence of concurrent viral infections [8], mycotoxin [9, 10] and nutrition [11] could aggravate the infection but the related pathogenic mechanisms are still unclear.

\footnotetext{
*Correspondence: cxx@njau.edu.cn

${ }^{1}$ College of Veterinary Medicine, Nanjing Agricultural University, Nanjing 210095, China

Full list of author information is available at the end of the article
}

Autophagy is an evolutionarily conserved catabolic process involved in the degradation and recycling of cytoplasmic components. It plays an essential role in normal development and responds to changing environmental stimuli $[12,13]$. Generally, autophagy is considered to be a defense mechanism against some viral infection by removing intracellular pathogens [14]. Conversely, a number of viruses have evolved diverse strategies to subvert autophagy for their own replication $[15,16]$. Some studies have shown that PCV2 infection triggers the autophagy pathway in host cells, which is essential for their own replication [17, 18]. Our previous studies demonstrated that oxidative stress can induce autophagy which facilitates PCV2 replication [6]. However, the mechanism involved in the promotion of PCV2 replication by oxidative stress-induced autophagy remains to be elucidated.

Apoptosis, also known as a programmed way of cell death, is an autonomous cell death based on a genetic program [13]. As a protective mechanism for the host, apoptosis plays an important role in maintaining the stability of the intracellular environment, regulating the 
differentiation of tissues and organs, and defending the cell against the infection with pathogenic microorganisms [19]. In some situation, the host cell can trigger apoptosis, a suicide way to protect the organism against the virus replication [20]. Inhibiting cellular apoptosis will facilitate some virus replication, assembly and spreading [21,22]. Although autophagy and apoptosis are two completely different cell processes, previous studies suggested that autophagy and apoptosis interact with each other under certain conditions, and this dynamic balance may affect virus replication [23]. For instance, classical swine fever virus-induced autophagy delays apoptosis and thus contributes to the persistent viral infection in host cells [24]. However, it is still unknown whether autophagy interacts with apoptosis in the promotion of PCV2 replication induced by oxidative stress.

The aim of this study was to investigate the role of autophagy and apoptosis in oxidative stress-promoted PCV2 replication in PK15 cells.

\section{Materials and methods Reagents and antibodies}

Bicinchoninic acid (BCA) protein assay kit (P0009), LDH cytotoxicity assay kit (C0016), enhanced chemiluminescence (ECL) kit (P0018M), MTT cell proliferation and cytotoxicity assay kit (C0009), Hoechst staining kit (C0003), benzyloxycarbonyl-Val-Ala-Asp fluoromethylketone (Z-VAD) (C1202), were obtained from Beyotime Institute of Biotechnology (Haimen, Jiangsu, China). Glutathione (GSH) assay kit was obtained from Nanjing Jiancheng Bioengineering Institute (Jiancheng, Nanjing, Jiangsu, China). Hydrogen peroxide $\left(\mathrm{H}_{2} \mathrm{O}_{2}\right)$ and 3-methyladenine (3-MA) were obtained from Sigma-Aldrich (St. Louis, USA). Rabbit monoclonal anti-caspase-3 (cleaved) antibody was obtained from Beyotime Institute of Biotechnology. Rabbit polyclonal anti-LC3B antibody and horseradish peroxidase (HRP)-conjugated goat antirabbit or -mouse secondary antibodies were purchased from Sigma-Aldrich. Mouse monoclonal anti- $\beta$-actin antibody and rabbit polyclonal anti-ATG5 antibody were purchased from Santa Cruz Biotechnology (Santa Cruz, USA). X-tremeGENE siRNA transfection regent was from Roche (Basel, Switzerland).

\section{Cells culture and viruses propagation}

Porcine kidney 15 (PK15) cells were gained from the China Institute of Veterinary Drug Control. PK15 cells were cultured in Dulbecco's modified Eagle's medium (DMEM, Invitrogen, Carlsbad, USA) supplemented with $8 \%$ newborn calf serum (NBCS), $100 \mu \mathrm{g} / \mathrm{mL}$ of streptomycin and $100 \mathrm{U} / \mathrm{mL}$ of penicillin at $37{ }^{\circ} \mathrm{C}$ with $5 \% \mathrm{CO}_{2}$ in a humidified atmosphere.
The PCV2 strain (PCV2NJ2002) was isolated from a kidney tissue sample of a pig with naturally occurring postweaning multisystemic wasting syndrome (PMWS). The identification of PCV type was performed by sequencing (Invitrogen, USA). PCV2 was propagated in PK15 cells as previously described [6]. The virus was stored at $-80^{\circ} \mathrm{C}$.

\section{MTT assay}

PK15 cells were seeded in a 96-well plate at a density of $5 \times 10^{3}$ cells/well for $24 \mathrm{~h}$ before the cells were treated with different concentrations of $\mathrm{H}_{2} \mathrm{O}_{2}$ for another $48 \mathrm{~h}$. Cytotoxicity was determined using colorimetric MTT assay kit following the manufacturer's protocol. Cells were treated with 3-(4, 5-cimethylthiazol-2-yl)-2, 5-diphenyl tetrazolium bromide (MTT) solution for $3 \mathrm{~h}$. Then medium was replaced by $150 \mu \mathrm{L}$ DMSO for $10 \mathrm{~min}$. Optical density (OD) was measured by a spectrophotometer at $490 \mathrm{~nm}$.

\section{LDH activity assay}

PK15 cells were seeded in a 96-well plate at a density of $5 \times 10^{3}$ cells/well for $24 \mathrm{~h}$ before the cells were treated with different concentrations of $\mathrm{H}_{2} \mathrm{O}_{2}$ for another $48 \mathrm{~h}$. LDH activity was determined by LDH cytotoxicity assay kit. After treatment, the 96-well plate was centrifuged at $400 \mathrm{~g}$ for $5 \mathrm{~min}$, and then the supernatant was collected and assayed following the manufacturer's instructions. Optical density (OD) was measured by a spectrophotometer at $490 \mathrm{~nm}$. LDH activity was normalized to protein concentrations and the results are expressed as percentage of the control values.

\section{Small interfering RNA (siRNA) transfection}

ATG5-specific siRNA and Control siRNA sequences were designed by Invitrogen. The ATG5-specific siRNA sequence was $5^{\prime}$-GCUUCGAGAUGUGUGGUUUtt- $3^{\prime}$, control siRNA sequence was $5^{\prime}$-CGUGUCACGUtt- $3^{\prime}$. PK15 cells were transfected with the targeted siRNA using the X-treame GENE siRNA transfection agent (Roche) according to the protocol provided by the manufacturer. Transfection reagent was incubated for $5 \mathrm{~h}$. The cells were then washed with DMEM and cultured for further treatments.

\section{Quantitative real-time PCR}

PCV2 DNA copies in PK15 cells were determined by quantitative real-time PCR. After treatment, the TaKaRa DNA Mini kit (TaKaRa, Dalian, China) was used to extract the PCV2 DNA. The purified DNA was used as a template for real-time PCR amplification. A 117bp region was amplified from PCV2 gene with a pair of PCV2-specific primers (forward primer: 5'-TAGTAT 
TCAAAGGGCACAG- $3^{\prime}$, reverse primer: $5^{\prime}$-AAGGCT ACCACAGTCAG-3'). Quantitative real-time PCR was performed using the ABI Prism Step One Plus detection system (Applied Biosystems, Foster city, USA). A recombinant pMD19 plasmid vector (TaKaRa) containing a PCV2 genome insert as a standard reference and PCV2 viral DNA was measured by the TaKaRa SYBR green real-time PCR kit.

\section{Cytokine mRNA Levels by Real-Time PCR}

The primers used were synthesized by Invitrogen (Paisley, Scotland, UK) (Table 1). PK15 cells were plated in a 12 -well plate at a density of $5 \times 10^{4}$ cells/well. After treatment, total RNA was isolated using the RNAiso Plus kit (TaKaRa) according to the manufacturer's instructions. The RNA quality was evaluated by the ratio of OD260/ OD280. Expression of genes was evaluated by real-time polymerase chain reaction (PCR) using the ABI Prism Step One Plus detection system (Applied Biosystems). A no-template control served as the negative control. The relative mRNA levels of each cytokine were assessed using the $2^{-\Delta \Delta C T}$ method and normalized to the housekeeping gene $\beta$-actin. Real time PCR was performed using SYBR Premix Ex TaqII (TaKaRa) and the ABI 7500 realtime PCR system.

\section{Indirect immunofluorescence assay (IFA)}

PCV2-infected PK15 cells were assayed by IFA. PK15 cells were plated in a 96-well plate at a density of $5 \times 10^{3}$ cells/well. After treatment, PK15 cells were fixed in $4 \%$ paraformaldehyde for $20 \mathrm{~min}$. After washed with PBST three times, the cells were permeabilised with $0.1 \%$ Triton $\mathrm{X}-100$ for $20 \mathrm{~min}$ and incubated in PBST containing $1 \%$ bovine serum albumin (BSA) at $37^{\circ} \mathrm{C}$ for $1 \mathrm{~h}$ to prevent nonspecific binding. Then, the cells were incubated with porcine anti-PCV2 antibody (UnivBiotech, Shanghai, China) at $37{ }^{\circ} \mathrm{C}$ for $1 \mathrm{~h}$, and

\section{Table 1 Primers used in this study}

\begin{tabular}{|c|c|}
\hline Gene & Primer sequence $\left(5^{\prime}-3^{\prime}\right)$ \\
\hline \multirow[t]{2}{*}{$\beta$-actin } & F: CTGCGGCATCCACGAAACT \\
\hline & R: AGGGCCGTGATCTCCTTCTG \\
\hline \multirow[t]{2}{*}{ Caspase-3 } & F: GGAATGGCATGTCGATCTGGT \\
\hline & R: ACTGTCCGTCTCAATCCCAC \\
\hline \multirow[t]{2}{*}{ Caspase- 8} & F:TCTGCGGACTGGATGTGATT \\
\hline & R:TCTGAGGTTGCTGGTCACAC \\
\hline \multirow[t]{2}{*}{ Bax } & F: ATGATCGCAGCCGTGGACACG \\
\hline & R: ACGAAGATGGTCACCGTCGC \\
\hline \multirow[t]{2}{*}{$\mathrm{BCl}-2$} & F: GAAACCCCTAGTGCCATCAA \\
\hline & R: GGGACGTCAGGTCACTGAAT \\
\hline
\end{tabular}

after three times washes with PBST, FITC-conjugated rabbit anti-pig antibody (Sigma) was added and incubated at $37^{\circ} \mathrm{C}$ for $1 \mathrm{~h}$. After three washes, the cells were observed under a fluorescence microscope. Cells positive for PCV2 viral antigens were counted in six fields of view. The calculation of the relative proportions of infected cells was based on the total amount of cells in each field.

\section{Determination of glutathione and intracellular ROS}

To detect the production of GSH, cells were harvested with PBS and then sonicated (Sonics VCX105). The cell homogenate was centrifuged at $12000 \mathrm{rpm}$ at $4{ }^{\circ} \mathrm{C}$ for $15 \mathrm{~min}$. The supernatant was collected, and the absorbance was assessed at $405 \mathrm{~nm}$ by glutathione (GSH) assay kit (Jiancheng, Nanjing, Jiangsu, China).

The amount of intracellular reactive oxygen species (ROS) was measured by the reactive oxygen species assay kit (Beyotime) according to the manufacturer instructions. Cells were incubated with DCFH-DA probes $(10 \mu \mathrm{M})$ for $30 \mathrm{~min}$ at $37^{\circ} \mathrm{C}$ in the dark. The ROS level was measured by fluorescence microscopy at $488 \mathrm{~nm}$ (excitation) and $581 \mathrm{~nm}$ (emission), and analyzed by Image-Pro Plus 6.0 software (Media Cybernetics, Sarasota, USA).

\section{Western blotting analysis}

The expression level of cleaved caspase-3, ATG5, LC3, cap, and $\beta$-actin were examined by Western blot. Cells were incubated under control and experimental conditions. After treatment, cells were collected and washed three times with ice-cold PBS followed by resuspension in RIPA buffer to prepare the whole cell lysates followed by centrifugation at $12000 \mathrm{rpm}$ for $20 \mathrm{~min}$ at $4{ }^{\circ} \mathrm{C}$. Protein concentrations were determined by the $\mathrm{BCA}$ protein assay kit (Beyotime Jiangsu, China). A total of $30 \mu \mathrm{g}$ of protein samples were diluted in $5 \times$ SDS-PAGE loading buffer and heated at $95^{\circ} \mathrm{C}$ for $5 \mathrm{~min}$. The samples were separated on $12 \%$ SDS-PAGE gels and transferred onto polyvinylidene fluoride (PVDF) membranes (Millipore, Molsheim, France). After blocking with $5 \%(\mathrm{w} / \mathrm{v})$ BSA in TBST for $2 \mathrm{~h}$, the membranes were incubated with primary antibodies overnight at $4{ }^{\circ} \mathrm{C}$. The membranes were washed with TBST three times and incubated with secondary antibody for $1 \mathrm{~h}$ at room temperature. Blots were visualized according to the standard enhanced chemiluminescence system (Bio-Rad, Berkeley, USA). Quantification of protein blots was performed using the Image-Pro Plus 6.0 software (Media Cybernetics, Sarasota, USA), and images were acquired from an EU-88 image scanner (Seiko Epson Corporation, Suwa, Japan). 
Analysis of apoptosis by Hoechst $\mathbf{3 3 2 5 8}$ staining

Apoptotic was detected by staining with the DNA binding fluorochrome Hoechst 33258. After treatment, cells were fixed with $4 \%$ formaldehyde. After staining with Hoechst solution, cells were washed again and observed under a fluorescence microscope (Zeiss) at $340 \mathrm{~nm}$.

\section{Statistical analysis}

Statistical analyses were performed using the GraphPad Prism version 6.0 (GraphPad Software, San Diego, CA, USA). All experiments were repeated at least three times and each experiment was carried out at least by triplicates. Data were analyzed using one-way analysis of variance (ANOVA) followed by least-significant difference test. Data are expressed as the mean \pm SEM. $P<0.05$ were considered statistical significant.

\section{Results}

\section{Cytotoxic effects of $\mathrm{H}_{\mathbf{2}} \mathrm{O}_{2}$ on PK15 cells}

The toxicity of $\mathrm{H}_{2} \mathrm{O}_{2}$ was assessed by MTT assay and LDH assay. PK15 cells were incubated with increasing concentrations of $\mathrm{H}_{2} \mathrm{O}_{2}(0-400 \mu \mathrm{M})$ for $48 \mathrm{~h}$. As shown in Figure $1 \mathrm{~A}$, after $\mathrm{H}_{2} \mathrm{O}_{2}$ exposure, there is a dose-dependent decrease in cell viability. The amounts of $\mathrm{LDH}$ in the supernatant medium indirectly reflect $\mathrm{H}_{2} \mathrm{O}_{2}$-induced cytotoxicity. As shown in Figure 1B, the release of LDH was significantly increased after cells were treated with $\mathrm{H}_{2} \mathrm{O}_{2}$ at the concentrations of $200 \mu \mathrm{M}$ and $400 \mu \mathrm{M}$, compared to the control group $(P<0.01)$. Therefore, $\mathrm{H}_{2} \mathrm{O}_{2}$ was used at the concentrations of 10,50 and $100 \mu \mathrm{M}$ for subsequent experiments.

\section{Oxidative stress promotes PCV2 replication and induces} autophagy in PCV2-infected cells

To investigate the effects of oxidative stress on PCV2 replication, $\mathrm{H}_{2} \mathrm{O}_{2}$ was used to induce oxidative stress in
PK15 cells. Cells were inoculated with PCV2 at a multiplicity of infection (MOI) of 1 and incubated with $\mathrm{H}_{2} \mathrm{O}_{2}$ for $72 \mathrm{~h}$. As shown in Figures $2 \mathrm{~A}-\mathrm{C}, 50 \mu \mathrm{M}$ and $100 \mu \mathrm{M}$ $\mathrm{H}_{2} \mathrm{O}_{2}$ treatments induced a significant increase in ROS level and a significant decrease in intracellular GSH level compared to the single PCV2-infected group $(P<0.01)$. Furthermore, $\mathrm{H}_{2} \mathrm{O}_{2}$ treatment promoted PCV2 replication. $50 \mu \mathrm{M}$ and $100 \mu \mathrm{M} \mathrm{H} \mathrm{H}_{2} \mathrm{O}_{2}$ significantly increased the number of PCV2-infected cells, the PCV2 DNA copies and the viral cap protein level compared to the single PCV2-infected group (Figures 2D-H) $(P<0.01)$. These results indicate that $\mathrm{H}_{2} \mathrm{O}_{2}$-induced oxidative stress promotes PCV2 replication.

Then we determined whether oxidative stress treatment in PCV2-infected PK15 cells can induce autophagy. Western blot assay was used to measure the conversion of LC3 and the expression of protein ATG5 since they are the autophagy markers. As shown in Figures $3 \mathrm{~A}-\mathrm{C}, \mathrm{H}_{2} \mathrm{O}_{2}$ treatment significantly increased the expression of protein LC3-II and ATG5. Then PK15 cells were transfected with green fluorescent protein-microtubule associated protein 1 light-chain 3 (GFP-LC3), a specific marker of autophagic vesicles and autophagic activity. The results showed that $\mathrm{H}_{2} \mathrm{O}_{2}$ treatment upregulated the accumulation of the GFP-LC3 dots, which was consistent with the result of Western blot assay. These results show that oxidative stress could promote PCV2 replication and induce autophagy in PCV2-infected cells.

\section{Autophagy inhibition decreases oxidative stress-promoted PCV2 replication}

To confirm the role of autophagy mechanism in oxidative stress-promoted PCV2 replication, autophagy inhibitor 3-MA or small interfering RNAs (siRNAs) targeting ATG5 were used to block autophagy. As demonstrated in Figures 4A-D, Both the 3-MA
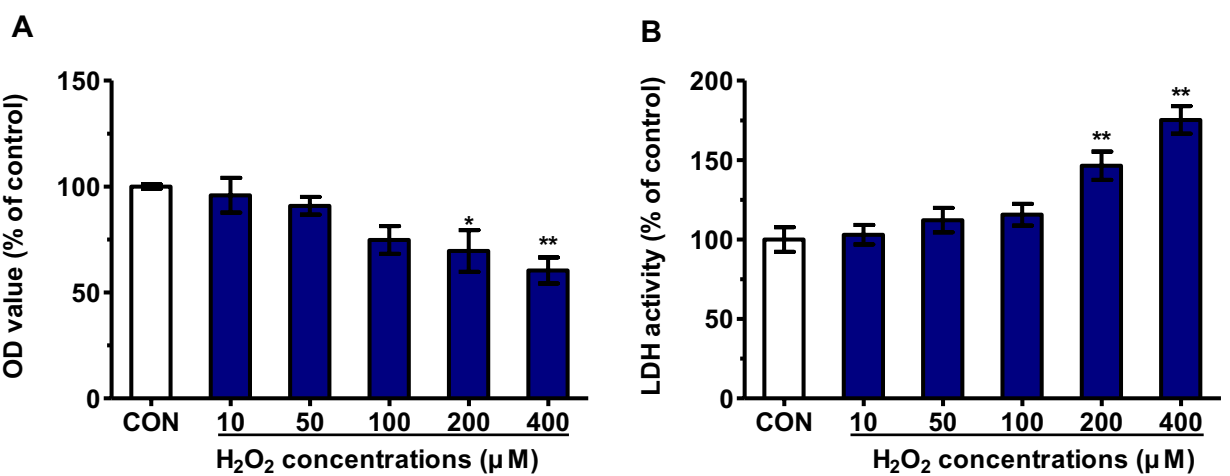

Figure 1 Cytotoxic effects of $\mathbf{H}_{2} \mathbf{O}_{2}$ on PK15 cells. PK15 cells were plated in 96-well plates at a density of $5 \times 10^{3}$ cells/well and cultured with $\mathrm{H}_{2} \mathrm{O}_{2}$ at different concentrations for $48 \mathrm{~h}$. Cell viability were determined by MTT assay $(\mathbf{A})$ and LDH activity assay (B). All results are presented as mean $\pm \operatorname{SEM}\left(n=5\right.$, each). Significance compared with control $\left({ }^{*} P<0.05\right.$ and $\left.{ }^{*} P<0.01\right)$. 


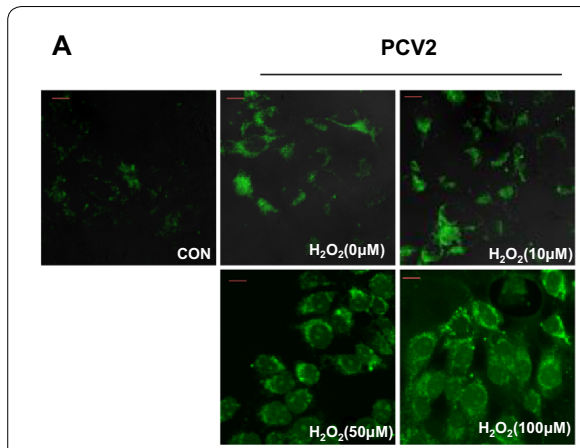

D
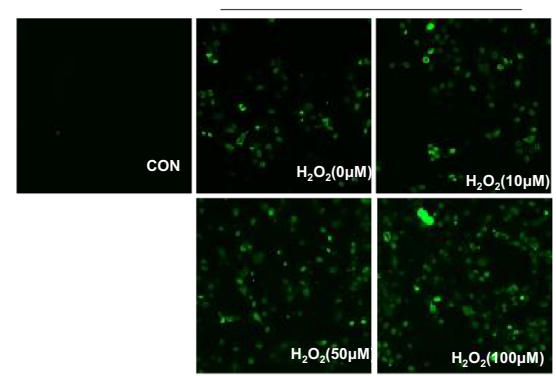

B

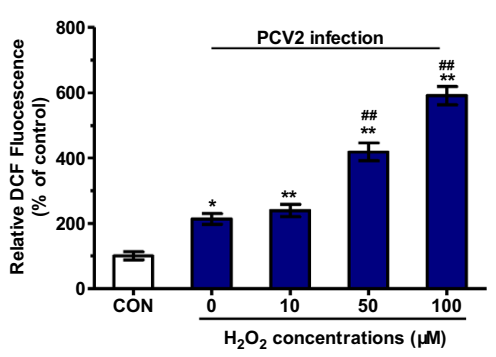

E

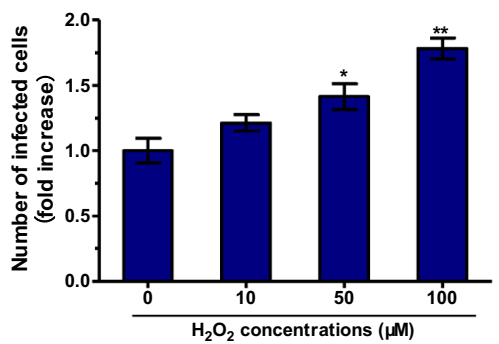

C

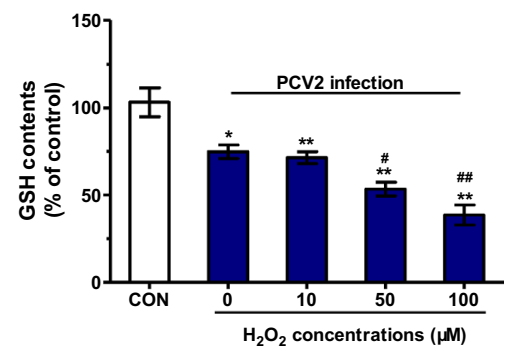

F

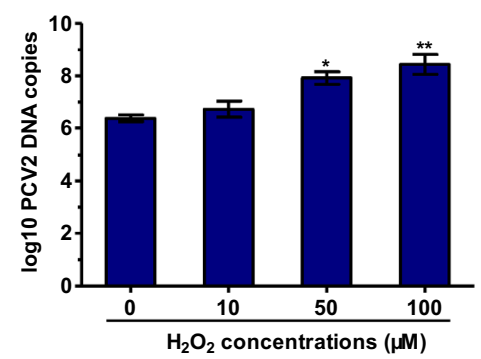

G

H
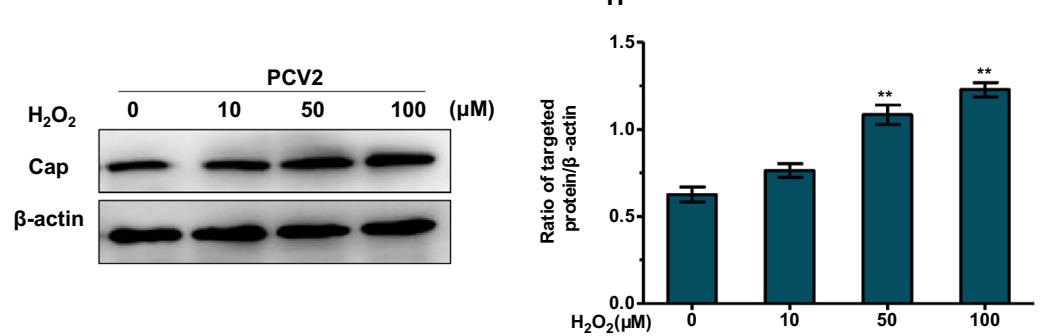

Figure 2 Oxidative stress promotes PCV2 replication in PCV2-infeced PK15 cells. PK15 cells were infected with PCV2 at MOI of 1 , after $2 \mathrm{~h}$ infection, the cells were further cultured in fresh medium with different concentrations of $\mathrm{H}_{2} \mathrm{O}_{2}$ for $48 \mathrm{~h}$. $\mathbf{A}$, $\mathbf{B}$ Cells were stained with $\mathrm{H} 2 \mathrm{DCF}-\mathrm{DA}$ to measure intracellular ROS. C The determination of GSH content was performed according to the procedures described in materials and methods. D, E The number of infected cells was detected by immunofluorescence assay. F Real-time PCR was used to detect the PCV2 viral DNA copies. G, $\mathbf{H}$ The expression of viral cap protein was detected by Western blotting. Scale bar: $10 \mu \mathrm{m}$. All results are presented as mean \pm SEM $(n=3$, each). Significance compared with control $\left({ }^{*} P<0.05\right.$ and $\left.{ }^{* *} P<0.01\right)$. Significance compared with single PCV2-infected group $\left({ }^{\#} P<0.05\right.$ and $\left.{ }^{\# \#} P<0.01\right)$.

treatment and ATG5 knockdown significantly reduced the ATG5 and LC3-II protein level compared to $\mathrm{H}_{2} \mathrm{O}_{2}$ treatment group $(P<0.01)$, and 3-MA treatment also downregulated the accumulation of the GFP-LC3 dots. Furthermore, 3-MA treatment and ATG5 knockdown significantly reduced viral cap protein level, the PCV2 DNA copies and the number of PCV2-infected cells, compared to the single PCV2-infected group $(P<0.05)$. These results show that autophagy inhibition could block oxidative stress-promoted PCV2 replication.

\section{Autophagy inhibition increases apoptosis in PCV2-infected PK15 cells}

Increasing evidence suggests that in some instances autophagy and apoptosis are cross inhibitory. To determine how oxidative stress-induced autophagy affects the infection of PCV2 in PK15 cells, apoptosis mechanism was investigated. We blocked autophagy with 3-MA or siATG5. Western bolt assay was used to detect the expression of apoptosis protein cleaved caspase-3. As shown in Figures 5A and B, autophagy 


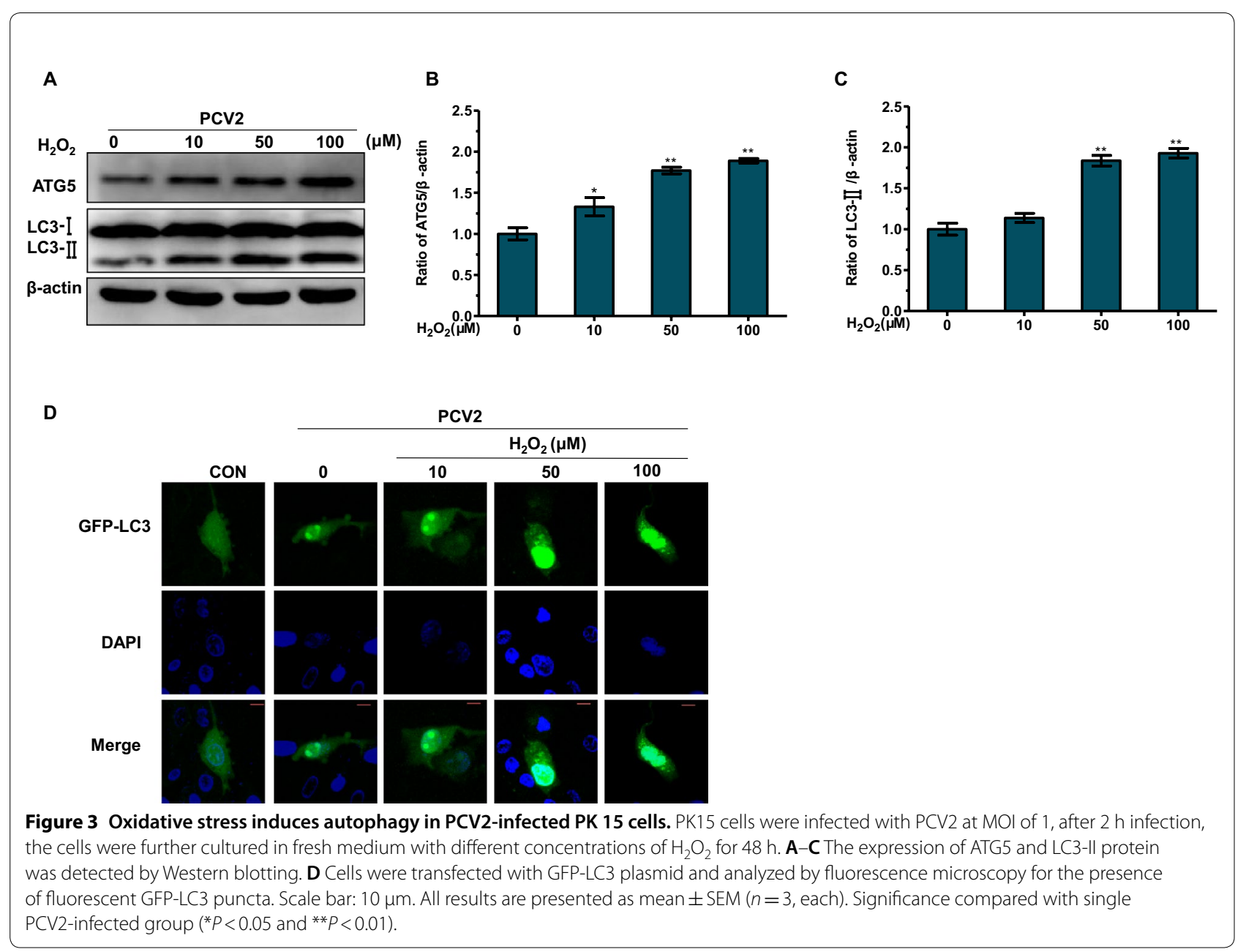

inhibition significantly increased the expression of cleaved caspase- 3 protein $(P<0.05)$. The mRNA levels of caspase 3 , caspase $8, \mathrm{Bax}$ and $\mathrm{Bcl}-2$ were also detected by RT-PCR. Treatment with 3-MA or transfection with the siATG5 significantly increased the mRNA levels of caspase 3 , caspase 8 and Bax, but decreased the Bcl-2 mRNA levels $(P<0.05)$.

The morphological changes of apoptotic cells were detected using Hoechst 33258 staining. Apoptosis was defined by morphologic changes in the nuclei such as chromatin condensation and nuclear fragmentation. As shown in Figure 5G, the number of cells with apoptotic characteristics enhanced when autophagy was suppressed. Similar results were obtained when autophagic activity was inhibited by knocking down ATG5. These results indicate that oxidative stressinduced autophagy could attenuate apoptosis.
Inhibition of apoptosis restores oxidative stress-promoted PCV2 replication

To further confirm whether autophagic machinery influences apoptosis during PCV2 infection, Z-VAD, an inhibitor of apoptosis was used. As shown in Figures 6A$\mathrm{E}$, suppression of apoptosis by Z-VAD in conditions of autophagy inhibition rescued host cells. Notably, Z-VAD treatment partially reversed the effects of autophagy inhibition on PCV2 replication $(P<0.05)$ (Figures $6 \mathrm{~F}-\mathrm{H}$ ). These results indicate that autophagy inhibition does not decrease persistent PCV2 infection if apoptosis is blocked.

\section{Discussion}

PCV2 is an emerging viral disease and a major factor affecting pig health [25]. It is linked to PCV2-associated diseases, which includes PMWS [26], porcine dermatitis 
A

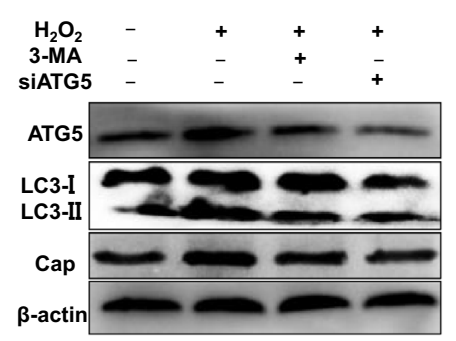

D
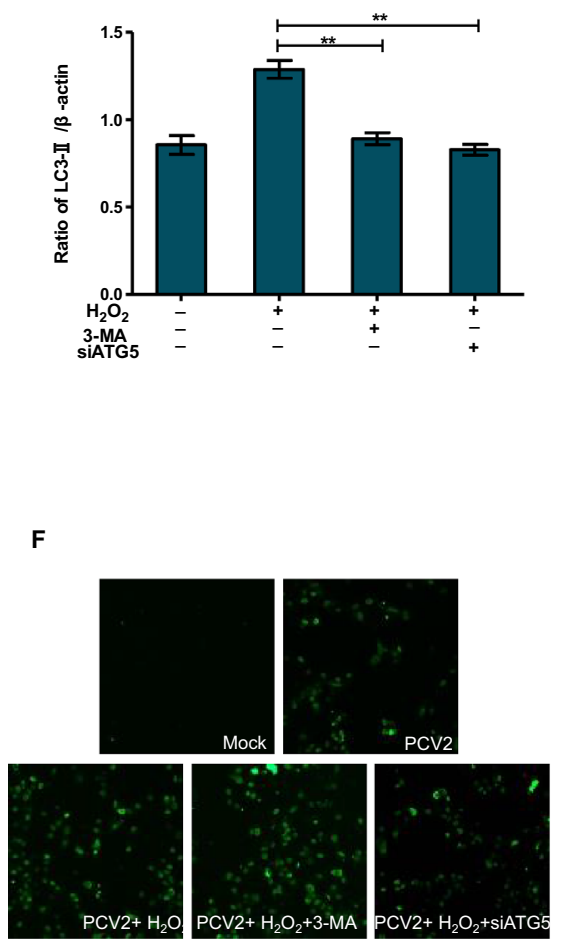

B

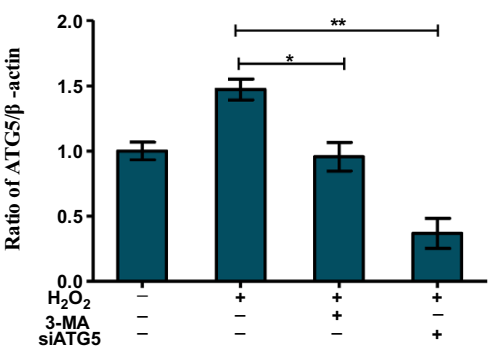

E

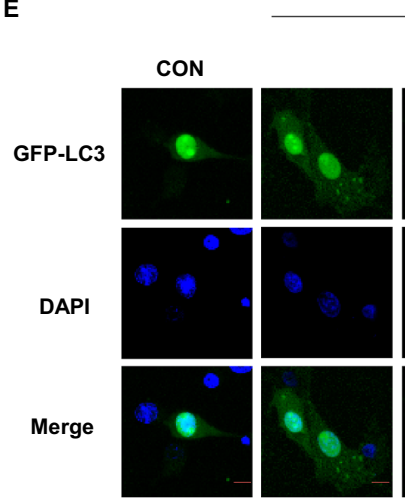

G

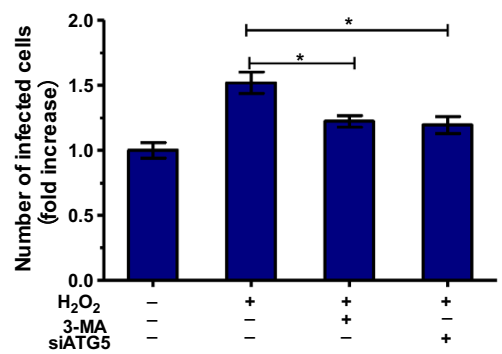

C

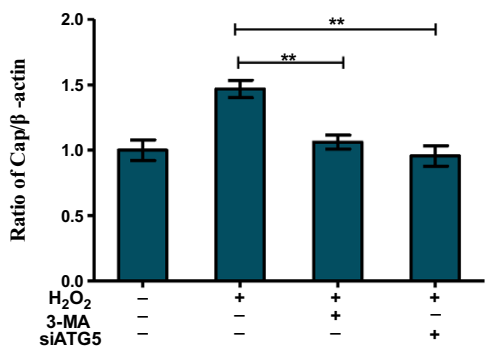

PCV2

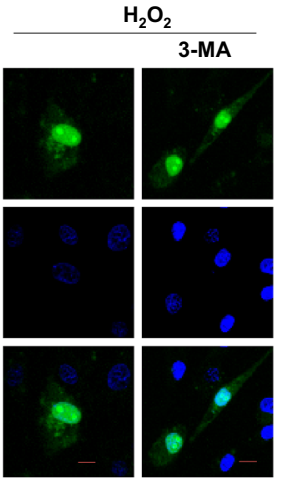

H

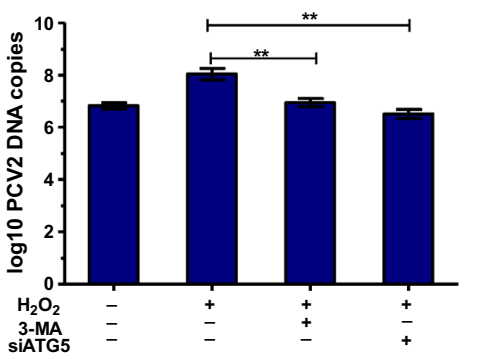

Figure 4 Autophagy inhibition decreases oxidative stress-promoted PCV2 replication. PK15 cells were infected with PCV2 at MOI of 1 , cells were pretreated with 3-MA (5 mM) or transfected with the siATG5 and then cultured with different concentrations of $\mathrm{H}_{2} \mathrm{O}_{2}$ for 48 h. A-D The expression of ATG5 and LC3-II protein was detected by Western blotting. E Cells were transfected with GFP-LC3 plasmid and analyzed by fluorescence microscopy for the presence of fluorescent GFP-LC3 puncta. Scale bar: $10 \mu \mathrm{m}$. F, G The number of infected cells was detected by immunofluorescence assay. $\mathbf{H}$ Real-time PCR was used to detect the PCV2 viral DNA copies. All results are presented as mean \pm SEM $(n=3$, each). Significance compared with PCV2-infected and $\mathrm{H}_{2} \mathrm{O}_{2}$ treatment group $\left({ }^{*} P<0.05\right.$ and $\left.{ }^{* *} P<0.01\right)$.

and nephropathy syndrome (PDNS) [27] and porcine respiratory disease complex (PRDC) [28]. The clinical signs of PCV2-associated diseases are nonspecific and variable. It can be subclinical or include one or more clinical manifestations [26]. Numerous cofactors have been shown to contribute to the development of PCV2-associated diseases. However, to date, the pathogenesis of PCV2 is still unclear.
Intracellular redox state is the result of mutual antagonism between the oxidant and the antioxidant processes [29]. Many studies have determined that ROS, key molecules accumulation of which leads to oxidative stress, can induce autophagy [30-32]. Both oxidative stress and autophagy may affect viral replication in the host cells [33]. It has been shown that PCV2 infection could cause ROS accumulation [6]. In addition, autophagy induced by 


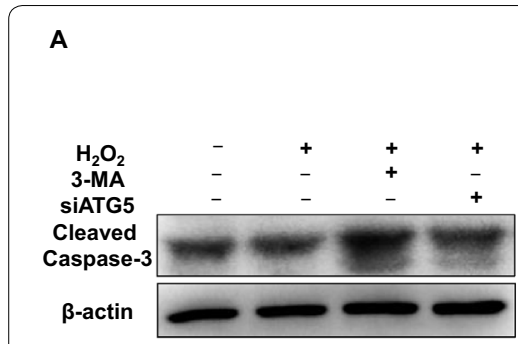

D

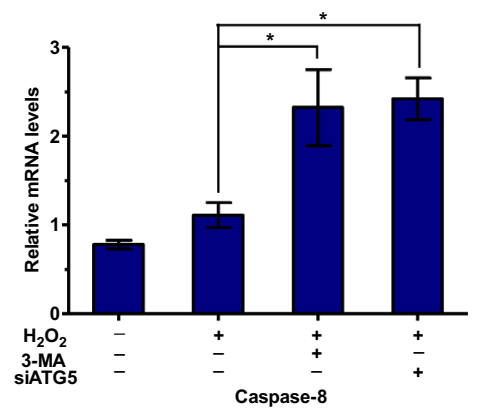

G
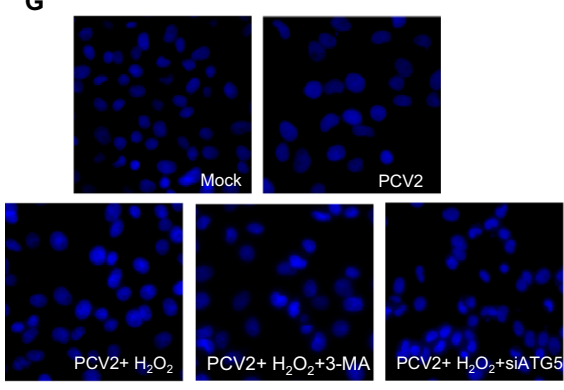

B

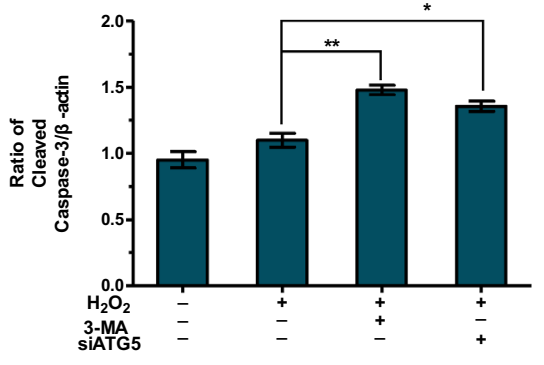

E

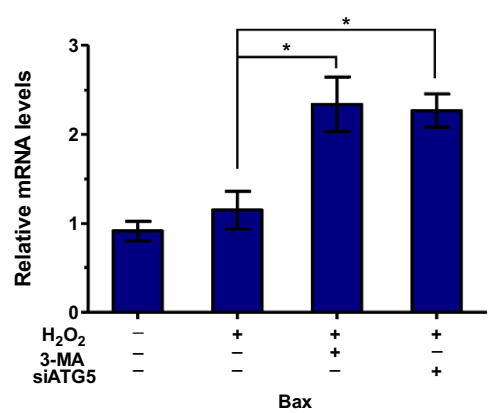

H

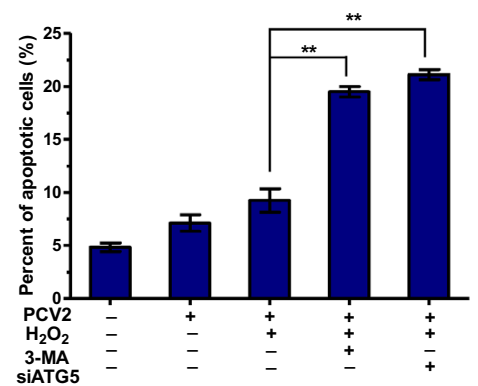

C

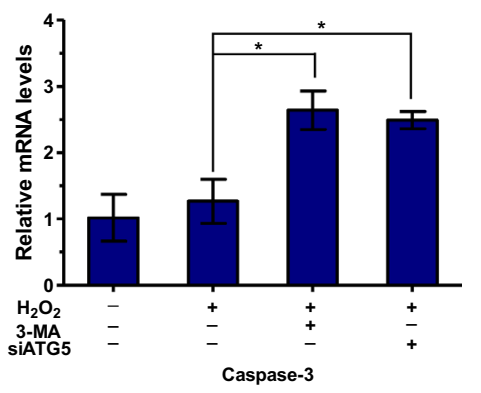

F

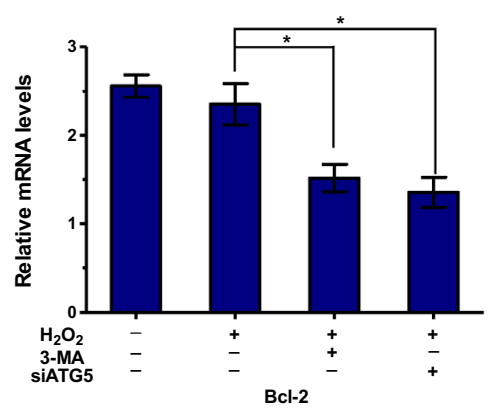

Figure 5 Autophagy inhibition increases apoptosis in PCV2-infected PK15 cells. PK15 cells were infected with PCV2 at MOI of 1, cells were pretreated with 3-MA or transfected with the siATG5 and then cultured in the presence of $\mathrm{H}_{2} \mathrm{O}_{2}$ for $48 \mathrm{~h}$. A, B The expression of cleaved caspase-3 protein was detected by Western blotting. C-F The mRNA levels of caspase-3, caspase-8, Bax and Bcl-2 was measured by RT-PCR. G, H Morphology of apoptotic cell nuclei was detected by staining Hoechst 33258. The data represent the mean \pm SEM $(n=3$, each). Significance compared with PCV2-infected and $\mathrm{H}_{2} \mathrm{O}_{2}$ treatment group ( ${ }^{*} P<0.05$ and $\left.{ }^{* *} P<0.01\right)$.

oxidative stress and PCV2 infection itself can also promote PCV2 infection and replication [9, 10, 17, 34, 35]. In this study, oxidative stress has been further confirmed to promote PCV2 replication in PK15 cells (Figure 2). Oxidative stress caused autophagy in PK15 cells by detecting the expression of LC3-II, ATG5, and the accumulation of GFP-LC3 dots (Figure 3). In contrast, this effect was suppressed by inhibiting autophagy by 3-MA or transfection with the siATG5 (Figure 4). These results suggest that oxidative stress could induce autophagy in PCV2infected PK15 cells which is responsible for PCV2 replication promotion.
Apoptosis and autophagy can antagonize or assist each other, thus differentially influencing cell fate. Many studies have shown the importance of the interaction between autophagy and apoptosis. For instance, Robin et al. have shown that differential expression of isoforms of pro-apoptotic protein TP53/p53, combined with the antagonism between apoptosis and autophagy, ensured the response to stress [36]. Beclin 1, an upstream molecule required for autophagosome formation, also regulates apoptosis by interacting with $\mathrm{Bcl}-2$ [37]. Obviously, in some cases, the same proteins have been shown as a link between autophagy and apoptosis, 

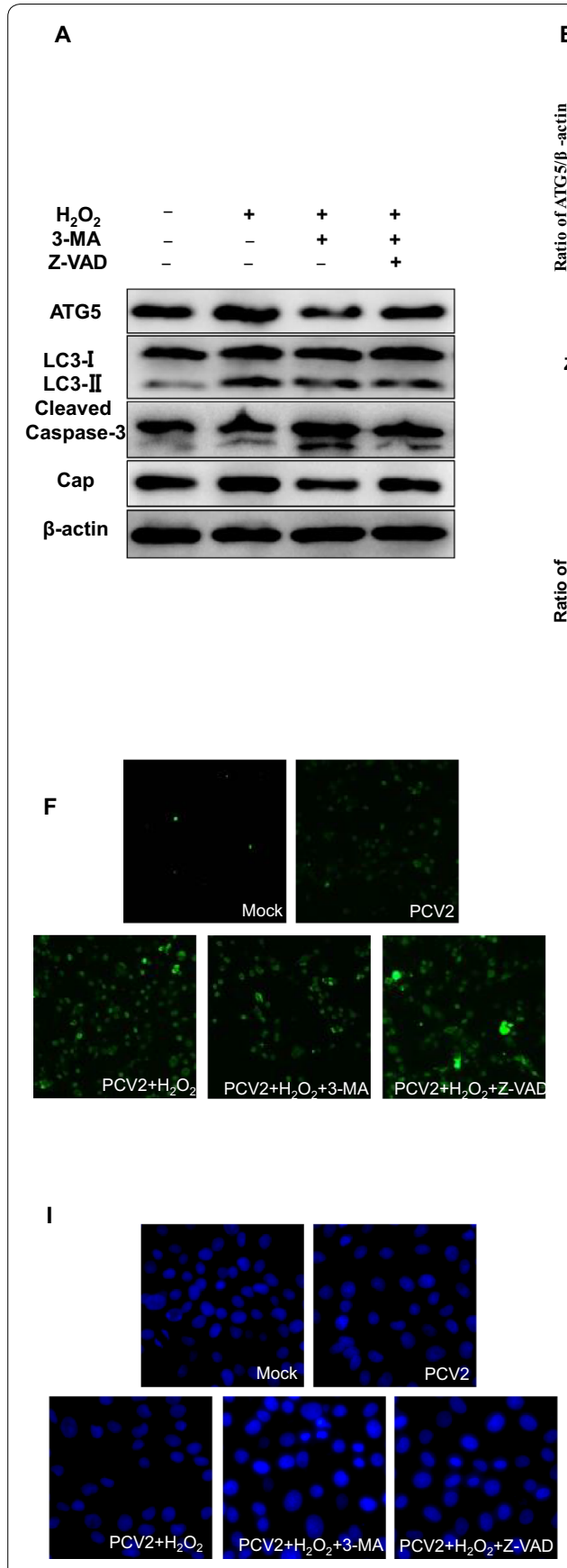
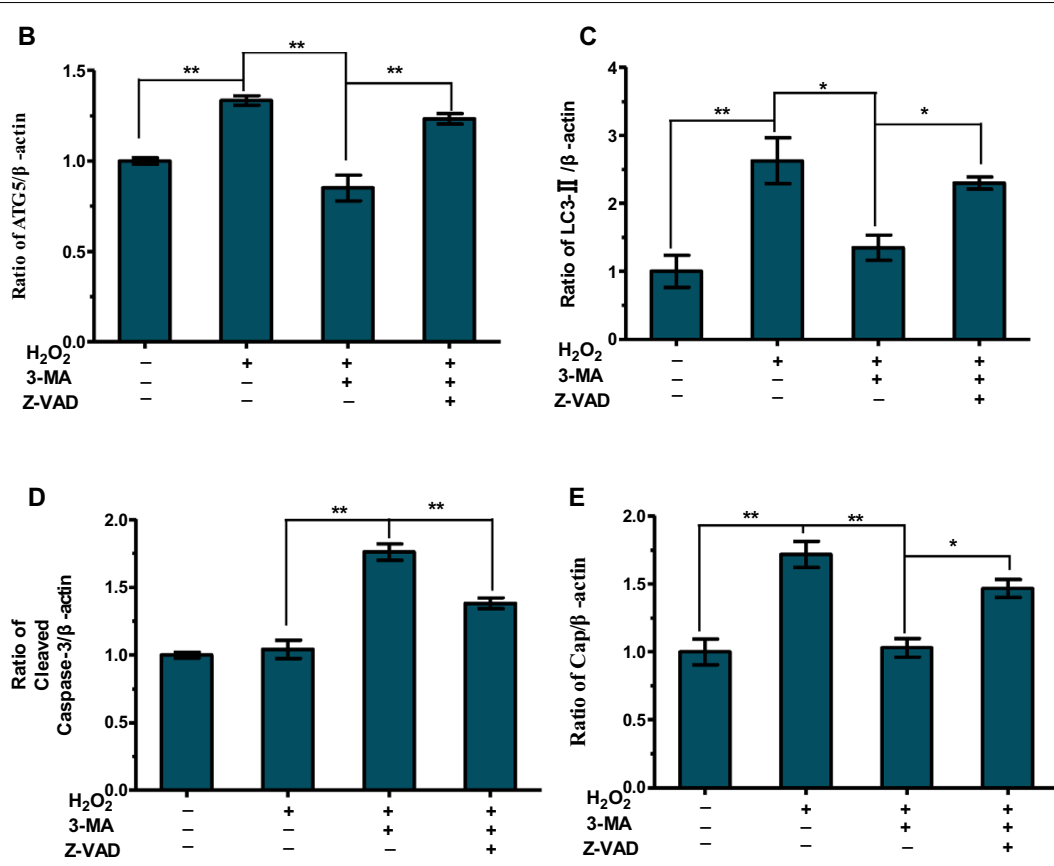

G

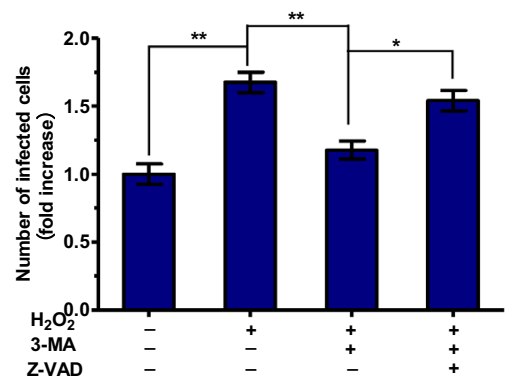

H

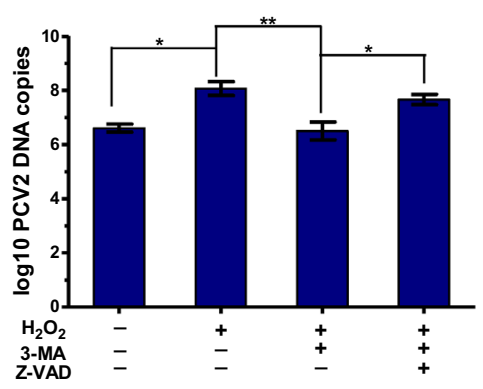

$\mathbf{J}$

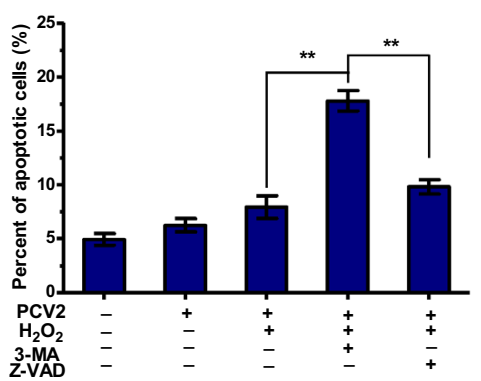

Figure 6 Inhibition of apoptosis restores oxidative stress-promoted PCV2 replication. PK15 cells were infected with PCV2 at MOI of 1, cells were pretreated with 3-MA or pretreated with 3-MA and Z-VAD $(10 \mu M)$, then cultured with $\mathrm{H}_{2} \mathrm{O}_{2}$. A-E The expression of ATG5, LC3-II, cleaved caspase-3 and cap protein were detected by Western blotting. F, G The number of infected cells was detected by immunofluorescence assay. $\mathbf{H}$ Real-time PCR was used to detect the PCV2 viral DNA copies. I, J Morphology of apoptotic cell nuclei was detected by staining Hoechst 33258 . The data represent the mean $\pm \operatorname{SEM}\left(n=3\right.$, each). Significance represent as ${ }^{*} P<0.05$ and ${ }^{* *} P<0.01$.

which regulates both autophagic and apoptotic processes at the cellular level and these processes can interact with each other under different environmental conditions. Previous study has shown that chikungunya virus can delay caspase-dependent apoptosis by inducing autophagy [38], indicating that autophagy favors the survival of host cells through the regulation of apoptosis and thus contributes to virus propagation. Previous 
studies have also shown that respiratory syncytial virus can increase cellular ROS levels and induce autophagy, but autophagy inhibition significantly deceased cell viability and increased cell apoptosis in HEp-2 cells [39]. Our results showed that autophagy inhibition decreased PCV2 replication and induced apoptosis (Figures 4 and 5). Z-VAD, an apoptosis inhibitor, can partially reverse the effects of autophagy inhibition on PCV2 replication (Figure 6). These results indicate that oxidative stress-induced autophagy mediated the inhibition of apoptosis, which is beneficial for the continued survival of host cells and persistent replication of PCV2. The role of apoptosis in PCV2 infection has also been demonstrated in other study, in which PCV2 ORF4 protein was found to directly inhibit cell apoptosis and then facilitate the early infection of PCV2 [40].

In summary, this study reveals that autophagy induced by oxidative stress promotes PCV2 replication in PK15 cells through inhibiting the apoptosis pathway and therefore contributes to persistent viral infection. Our study provides a novel insight into the role of interplay between autophagy and apoptosis in PCV2 replication promoted by oxidative stress. Our findings can partly interpret the pathogenic mechanism of PCV2 related to the oxidative stress-induced autophagy.

\begin{abstract}
Abbreviations
PCV2: porcine circovirus type 2; ROS: reactive oxygen species; Z-VAD: benzyloxycarbonyl-Val-Ala-Asp fluoromethylketone; $\mathrm{H}_{2} \mathrm{O}_{2}$ : hydrogen peroxide; NBCS: newborn calf serum; MTT: 3-(4, 5-dimethylthiazol-2-yl)-2, 5-diphenyl2H-tetrazolium bromide; DMEM: Dulbecco's modified Eagle's medium; 3-MA: 3-methyladenine; ANOVA: one-way analysis of variance; IFA: Indirect immunofluorescence assay; PBS: phosphate-buffered saline; PMWS: postweaning multisystemic wasting syndrome; MOI: multiplicity of infection.
\end{abstract}

\section{Competing interests}

The authors declare that they have no competing interests.

\section{Authors' contributions}

NZ participated in the design of the study, performed the laboratory tests and drafted the manuscript. KL, HL, ZL, HW, VIK, BC, CP, FG contributed to the design, coordination and execution of the field trial. $\mathrm{XC}$ and $\mathrm{KH}$ conceived the study and participated in its design. All authors read and approved the final manuscript.

\section{Author details \\ ${ }^{1}$ College of Veterinary Medicine, Nanjing Agricultural University, Nan- jing 210095, China. ${ }^{2}$ Institute for Cell and Molecular Biosciences, Newcastle University, Newcastle upon Tyne NE4 5PL, UK. ${ }^{3}$ Present Address: School of Biochemistry, University of Bristol, Bristol BS8 1TS, UK.}

\section{Funding}

This work was funded by an international collaboration grant to Viktor I. Korolchuk and Xingxiang Chen from The Royal Society and National Natural Science Foundation of China (NSFC) (31811530300), the Priority Program Development of Jiangsu Higher Education Institutions (Jiangsu, China), MOE Joint International Research Laboratory of Animal Health and Food Safety, College of Veterinary Medicine, Nanjing Agricultural University, and Project of National Center for International Research on Animal Gut Nutrition.

\section{Publisher's Note}

Springer Nature remains neutral with regard to jurisdictional claims in published maps and institutional affiliations.

Received: 2 January 2019 Accepted: 14 February 2019

Published online: 05 March 2019

\section{References}

1. Opriessnig T, Langohr I (2013) Current state of knowledge on porcine circovirus type 2-associated lesions. Vet Pathol 50:23-38

2. Grau-Roma L, Fraile L, Segales J (2011) Recent advances in the epidemiology, diagnosis and control of diseases caused by porcine circovirus type 2. Vet J 187:23-32

3. Ge X, Wang F, Guo X, Yang H (2012) Porcine circovirus type 2 and its associated diseases in China. Virus Res 164:100-106

4. Lager KM, Gauger PC, Vincent AL, Opriessnig T, Kehrli ME Jr, Cheung AK (2007) Mortality in pigs given porcine circovirus type 2 subgroup 1 and 2 viruses derived from DNA clones. Vet Rec 161:428-429

5. Scherz-Shouval R, Shvets E, Fass E, Shorer H, Gil L, Elazar Z (2007) Reactive oxygen species are essential for autophagy and specifically regulate the activity of Atg4. EMBO J 26:1749-1760

6. Chen X, Ren F, Hesketh J, Shi X, Li J, Gan F, Huang K (2012) Reactive oxygen species regulate the replication of porcine circovirus type 2 via NF-KB pathway. Virology 426:66-72

7. Grasland B, Loizel C, Blanchard P, Oger A, Nignol AC, Bigarre L, Morvan H, Cariolet R, Jestin A (2005) Reproduction of PMWS in immunostimulated SPF piglets transfected with infectious cloned genomic DNA of type 2 porcine circovirus. Vet Res 36:685-697

8. Opriessnig T, McKeown NE, Harmon KL, Meng XJ, Halbur PG (2006) Porcine circovirus type 2 infection decreases the efficacy of a modified live porcine reproductive and respiratory syndrome virus vaccine. Clin Vaccine Immunol 13:923-929

9. Qian G, Liu D, Hu J, Gan F, Hou L, Chen X, Huang K (2017) Ochratoxin A-induced autophagy in vitro and in vivo promotes porcine circovirus type 2 replication. Cell Death Dis 8:e2909

10. Gan F, Zhang Z, Hu Z, Hesketh J, Xue H, Chen X, Hao S, Huang Y, Cole Ezea P, Parveen F, Huang K (2015) Ochratoxin A promotes porcine circovirus type 2 replication in vitro and in vivo. Free Radic Biol Med 80:33-47

11. Tomas A, Fernandes LT, Valero O, Segales J (2008) A meta-analysis on experimental infections with porcine circovirus type 2 (PCV2). Vet Microbiol 132:260-273

12. Mizushima N (2007) Autophagy: process and function. Genes Dev 21:2861-2873

13. Wallach D, Kang TB, Dillon CP, Green DR (2016) Programmed necrosis in inflammation: toward identification of the effector molecules. Science 352:aaf2154

14. Shoji-Kawata S, Levine B (2009) Autophagy, antiviral immunity, and viral countermeasures. Biochim Biophys Acta 1793:1478-1484

15. Wong J, Zhang J, Si X, Gao G, Mao I, McManus BM, Luo H (2008) Autophagosome supports coxsackievirus B3 replication in host cells. J Virol 82:9143-9153

16. Lee YR, Lei HY, Liu MT, Wang JR, Chen SH, Jiang-Shieh YF, Lin YS, Yeh TM, Liu CC, Liu HS (2008) Autophagic machinery activated by dengue virus enhances virus replication. Virology 374:240-248

17. Zhu B, Zhou Y, Xu F, Shuai J, Li X, Fang W (2012) Porcine circovirus type 2 induces autophagy via the AMPK/ERK/TSC2/mTOR signaling pathway in PK-15 cells. JVirol 86:12003-12012

18. Gu Y, Qi B, Zhou Y, Jiang X, Zhang X, Li X, Fang W (2016) Porcine circovirus type 2 activates CaMMKbeta to initiate autophagy in PK-15 cells by increasing cytosolic calcium. Viruses 8:E135

19. Shi M, Zhou H, Lei M, Chen L, Zellmer L, He Y, Yang W, Xu N, Liao DJ (2018) Spontaneous cancers, but not many induced ones in animals, resemble semi-new organisms that possess a unique programmed cell death mode different from apoptosis, senescent death, necrosis and stressinduced cell death. J Cancer 9:4726-4735

20. Everett H, McFadden G (1999) Apoptosis: an innate immune response to virus infection. Trends Microbiol 7:160-165 
21. Neumann S, El Maadidi S, Faletti L, Haun F, Labib S, Schejtman A, Maurer U, Borner C (2015) How do viruses control mitochondria-mediated apoptosis? Virus Res 209:45-55

22. Benedict CA, Norris PS, Ware CF (2002) To kill or be killed: viral evasion of apoptosis. Nat Immunol 3:1013-1018

23. Marino G, Niso-Santano M, Baehrecke EH, Kroemer G (2014) Self-consumption: the interplay of autophagy and apoptosis. Nat Rev Mol Cell Biol 15:81-94

24. Pei J, Deng J, Ye Z, Wang J, Gou H, Liu W, Zhao M, Liao M, Yi L, Chen J (2016) Absence of autophagy promotes apoptosis by modulating the ROS-dependent RLR signaling pathway in classical swine fever virusinfected cells. Autophagy 12:1738-1758

25. Patterson AR, Opriessnig T (2010) Epidemiology and horizontal transmission of porcine circovirus type 2 (PCV2). Anim Health Res Rev 11:217-234

26. Segales J, Sitjar M, Domingo M, Dee S, Del Pozo M, Noval R, Sacristan C, De las Heras A, Ferro A, Latimer KS (1997) First report of post-weaning multisystemic wasting syndrome in pigs in Spain. Vet Rec 141:600-601

27. Rosell C, Segales J, Ramos-Vara JA, Folch JM, Rodriguez-Arrioja GM, Duran CO, Balasch M, Plana-Duran J, Domingo M (2000) Identification of porcine circovirus in tissues of pigs with porcine dermatitis and nephropathy syndrome. Vet Rec 146:40-43

28. Grau-Roma L, Segales J (2007) Detection of porcine reproductive and respiratory syndrome virus, porcine circovirus type 2, swine influenza virus and Aujeszky's disease virus in cases of porcine proliferative and necrotizing pneumonia (PNP) in Spain. Vet Microbiol 119:144-151

29. Schafer FQ, Buettner GR (2001) Redox environment of the cell as viewed through the redox state of the glutathione disulfide/glutathione couple. Free Radic Biol Med 30:1191-1212

30. Hui KF, Yeung PL, Chiang AK (2016) Induction of MAPK- and ROS-dependent autophagy and apoptosis in gastric carcinoma by combination of romidepsin and bortezomib. Oncotarget 7:4454-4467

31. Poillet-Perez L, Despouy G, Delage-Mourroux R, Boyer-Guittaut M (2015) Interplay between ROS and autophagy in cancer cells, from tumor initiation to cancer therapy. Redox Biol 4:184-192
32. Dewaele M, Maes H, Agostinis P (2010) ROS-mediated mechanisms of autophagy stimulation and their relevance in cancer therapy. Autophagy 6:838-854

33. Michalek RD, Pellom ST, Holbrook BC, Grayson JM (2008) The requirement of reactive oxygen intermediates for lymphocytic choriomeningitis virus binding and growth. Virology 379:205-212

34. Shen XL, Zhang B, Liang $R$, Cheng WH, Xu W, Luo Y, Zhao C, Huang $K$ (2014) Central role of Nix in the autophagic response to ochratoxin A. Food Chem Toxicol 69:202-209

35. Liu D, Lin J, Su J, Chen X, Jiang P, Huang K (2018) Glutamine deficiency promotes PCV2 infection through induction of autophagy via activation of ROS-mediated JAK2/STAT3 signaling pathway. J Agric Food Chem 66:11757-11766

36. Robin M, Issa AR, Santos CC, Napoletano F, Petitgas C, Chatelain G, Ruby M, Walter L, Birman S, Domingos PM, Calvi BR, Mollereau B (2018) Drosophila p53 integrates the antagonism between autophagy and apoptosis in response to stress. Autophagy. https://doi.org/10.1080/15548 627.2018.1558001

37. Pattingre S, Tassa A, Qu X, Garuti R, Liang XH, Mizushima N, Packer M, Schneider MD, Levine B (2005) Bcl-2 antiapoptotic proteins inhibit Beclin 1-dependent autophagy. Cell 122:927-939

38. Joubert PE, Werneke SW, de la Calle C, Guivel-Benhassine F, Giodini A, Peduto L, Levine B, Schwartz O, Lenschow DJ, Albert ML (2012) Chikungunya virus-induced autophagy delays caspase-dependent cell death. J Exp Med 209:1029-1047

39. Li M, Li J, Zeng R, Yang J, Liu J, Zhang Z, Song X, Yao Z, Ma C, Li W, Wang K, Wei L (2018) Respiratory syncytial virus replication is promoted by autophagy-mediated inhibition of apoptosis. J Virol 92:e02193-17

40. Lv Q, Guo K, Zhang G, Zhang Y (2016) The ORF4 protein of porcine circovirus type 2 antagonizes apoptosis by stabilizing the concentration of ferritin heavy chain through physical interaction. J Gen Virol 97:1636-1646
Ready to submit your research? Choose BMC and benefit from:

- fast, convenient online submission

- thorough peer review by experienced researchers in your field

- rapid publication on acceptance

- support for research data, including large and complex data types

- gold Open Access which fosters wider collaboration and increased citations

- maximum visibility for your research: over 100M website views per year

At BMC, research is always in progress.

Learn more biomedcentral.com/submissions 